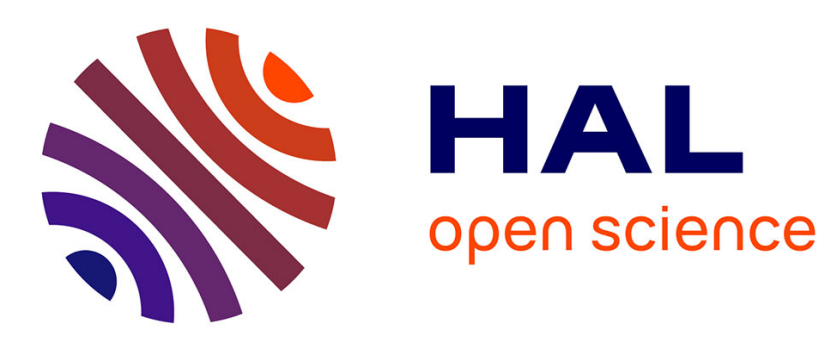

\title{
Dipole allowed transitions in GdF: A four-component relativistic general open-shell configuration interaction study.
}

Shigeyoshi Yamamoto, Hiroshi Tatewaki, Trond Saue

\section{- To cite this version:}

Shigeyoshi Yamamoto, Hiroshi Tatewaki, Trond Saue. Dipole allowed transitions in GdF: A fourcomponent relativistic general open-shell configuration interaction study.. Journal of Chemical Physics, 2008, 129 (24), pp.244505. 10.1063/1.3039794 . hal-00762461

\section{HAL Id: hal-00762461 \\ https://hal.science/hal-00762461}

Submitted on 21 Jan 2020

HAL is a multi-disciplinary open access archive for the deposit and dissemination of scientific research documents, whether they are published or not. The documents may come from teaching and research institutions in France or abroad, or from public or private research centers.
L'archive ouverte pluridisciplinaire HAL, est destinée au dépôt et à la diffusion de documents scientifiques de niveau recherche, publiés ou non, émanant des établissements d'enseignement et de recherche français ou étrangers, des laboratoires publics ou privés. 


\section{Dipole allowed transitions in GdF: A four- component relativistic general open-shell configuration interaction study}

Cite as: J. Chem. Phys. 129, 244505 (2008); https://doi.org/10.1063/1.3039794

Submitted: 05 October 2008 . Accepted: 11 November 2008 . Published Online: 29 December 2008

Shigeyoshi Yamamoto, Hiroshi Tatewaki, and Trond Saue

ARTICLES YOU MAY BE INTERESTED IN

Electronic spectra of DyF studied by four-component relativistic configuration interaction methods

The Journal of Chemical Physics 142, 094312 (2015); https://doi.org/10.1063/1.4913631

Electronic spectra of GdF reanalyzed by decomposing state functions according to f-shell angular momentum

The Journal of Chemical Physics 134, 164310 (2011); https://doi.org/10.1063/1.3583367

An atomic mean-field spin-orbit approach within exact two-component theory for a nonperturbative treatment of spin-orbit coupling

The Journal of Chemical Physics 148, 144108 (2018); https://doi.org/10.1063/1.5023750

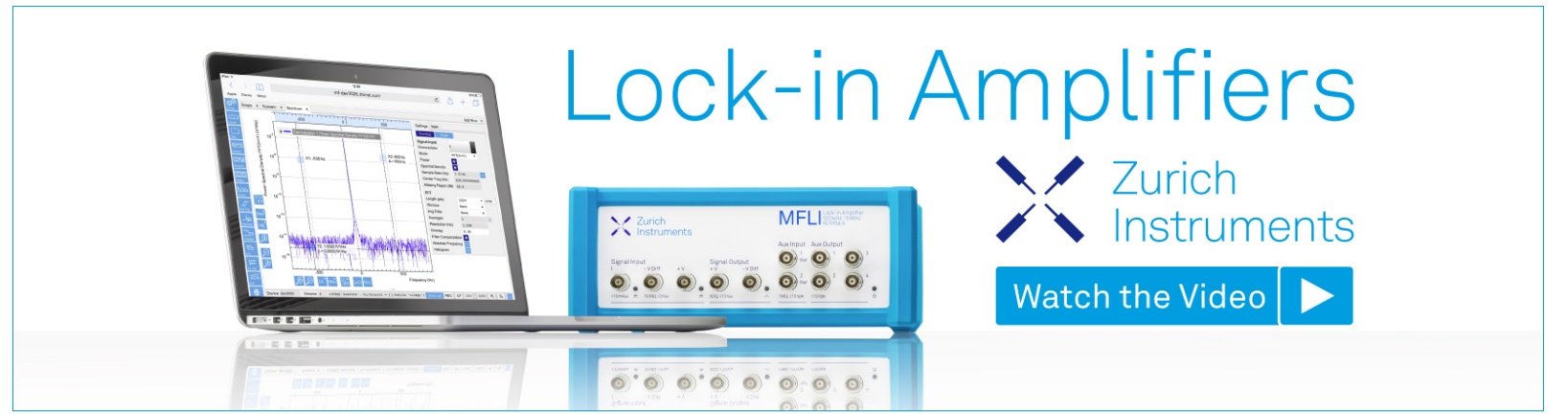

J. Chem. Phys. 129, 244505 (2008); https://doi.org/10.1063/1.3039794

(c) 2008 American Institute of Physics. 


\title{
Dipole allowed transitions in GdF: A four-component relativistic general open-shell configuration interaction study
}

\author{
Shigeyoshi Yamamoto, ${ }^{1}$ Hiroshi Tatewaki, ${ }^{2, a)}$ and Trond Saue ${ }^{3}$ \\ ${ }^{1}$ School of International Liberal Studies, Chukyo University, 101-2 Yagoto-Honmachi, Showa-ku, Nagoya, \\ Aichi 466-8666, Japan \\ ${ }^{2}$ Graduate School of Natural Sciences, Nagoya City University, Nagoya, Aichi 467-8501, Japan \\ ${ }^{3}$ Institute de Chimie de Strasbourg, Laboratoire de Chimie Quantique, LC3-UMR 7177 CNRS/Université \\ Louis Pasteur, 4 Rue Blaise Pascal, F-67070 Strasbourg, France
}

(Received 5 October 2008; accepted 11 November 2008; published online 29 December 2008)

\begin{abstract}
A four-component relativistic study of electronic transitions in the gadolinium monofluoride molecule $(\mathrm{GdF})$ is presented. The electronic spectra of GdF have been investigated with a general open-shell configuration interaction method, where active electrons are distributed among molecular spinors mainly consisting of the Gd $4 f, 5 d$, and $6 s$ atomic spinors. The near-degeneracy effects of these spinors on the molecular electronic structure are considered by the valence full-CI-like approach. By the magnitudes of calculated transition dipole moments, the candidates for the observable transitions were selected. The present result is complementary to our previous study based on multireference configuration interaction singles and doubles calculations, which identified the electronic excited states of GdF by comparing the calculated excitation energies and angular momenta with those given by the laser spectroscopy. The spectra of the excited states less than 3.0 $\mathrm{eV}$ have been refined with the help of the calculated transition probabilities. The transitions between the excited states are newly analyzed and a rearrangement is proposed. (C) 2008 American Institute of Physics. [DOI: 10.1063/1.3039794]
\end{abstract}

\section{INTRODUCTION}

The electronic spectra of lanthanide fluorides have been investigated experimentally by several groups. ${ }^{1-7}$ In particular, Kaledin et $a .^{7}$ performed an intensive investigation of the $\mathrm{GdF}$ molecule. Most of the excited states of GdF up to about $3.0 \mathrm{eV}$ above the ground state have been characterized by them. They also performed ligand field theory (LFT) calculations which gave results consistent with experiment, but some uncertainties still remain.

Several computational studies of the ground state of $\mathrm{GdF}$ (Refs. 8-14) have been published. However, studies of the excited states are scarce. We therefore performed $a b$ initio all-electron four-component configuration interaction (CI) calculations on $\mathrm{GdF}$ in a previous paper ${ }^{15}$ to clarify its electronic spectrum. This CI was multireference CI singles and doubles (MRCISD) based on the reduced frozen core approximation. ${ }^{16,17}$ The number of the reference functions was in the range from one to five. The active spinors in the CI calculations were as follows:

$$
\begin{aligned}
\mathrm{Gd}: & {[\mathrm{Cd}](5 p)^{6}(6 s)^{2}(5 d)^{1}(4 f)^{7}(25 / 18 / 15 / 10 / 1) /[2 / 5 / 4 / 5 / 1] } \\
& \text { for }\left(s_{+} / p_{ \pm} / d_{ \pm} / f_{ \pm} / g_{ \pm}\right), \\
\mathrm{F}: \quad[\mathrm{He}](2 s)^{2}(2 p)^{5}(12 / 8 / 2) /[3 / 5 / 2] & \\
& \text { for }\left(s_{+} / p_{ \pm} / d_{ \pm}\right) .
\end{aligned}
$$

Here, the numbers in parentheses and in square brackets show primitive and contracted Gaussian-type functions, respectively.

\footnotetext{
${ }^{a)}$ Electronic mail: htatewak@nsc.nagoya-cu.ac.jp.
}

The result of this MRCISD calculation is summarized in Table IX of the previous paper. ${ }^{15}$ Let us repeat its essence. The ground state of $\mathrm{GdF}$ is written as $\mathrm{Gd}^{+} \mathrm{F}^{-}(\Omega=7 / 2)$, where the electronic configuration of $\mathrm{Gd}$ is $(4 f)^{7}(6 s)^{2}$. A $5 d$ electron of $\mathrm{Gd}$ is moved to $\mathrm{F}$. The excited state designated as [15.8] observed $1.956 \mathrm{eV}\left(15776.9 \mathrm{~cm}^{-1}\right)$ above the ground state is calculated to be $\Omega=7 / 2,(4 f)^{7}\left(5 d_{+}\right)^{1}(6 s)^{1}$ of excitation energy $1.829 \mathrm{eV}$, being in good agreement with the assignment by Kaledin et al. ${ }^{7}$ Similarly, the excited state designated as [18.3] observed at $2.264 \mathrm{eV}\left(18261.9 \mathrm{~cm}^{-1}\right)$ is calculated to be $\Omega=9 / 2,(4 f)^{7}\left(5 d_{-}+5 d_{+}\right)^{1}(6 s)^{1}$ of excitation energy $1.974 \mathrm{eV}$. Its angular momentum $(\Omega=9 / 2)$ did not agree with $\Omega=7 / 2$ assigned by Kaledin et al.

In the previous MRCISD study we identified the excited states on the basis of their excitation energies and their $\Omega$ values. The result is mostly consistent with the assignment by Kaledin et $a l .{ }^{7}$ However, the spectra are very complicated and therefore the assignment based merely on the excitation energies and angular momenta has some uncertainties. In addition, the $4 f$ molecular spinors are nearly degenerate and the $4 f$ electrons can easily have various configurations of ${ }^{8} \Sigma^{-}$. However, MRCISD with only a few reference functions cannot treat such a multiconfigurational effect, which suggests that MRCISD with more reference functions or multielectron excitation CI (such as valence full CI) is needed to clarify the electronic structure of the excited states. In addition, the observed transitions between the excited states are left unresolved.

In order to solve the problems described above, we have in the present study performed $a b$ initio all-electron fourcomponent general open-shell CI (GOSCI) calculations, 
where the full configurations are generated within the $(4 f)$ and $(5 d, 6 s)$ spaces. This type of CI yields many configurations, and accordingly increases the number of possible transitions between states, which in turn complicates the analysis. We have developed a code to calculate transition density matrices and transition dipole moments in a development version of the DIRAC program system. ${ }^{18}$ This program helps us to eliminate unimportant transitions based on the transition probabilities and enables us to concentrate our attention on the analysis of the promising candidates for the observed transitions. Since the electron correlation effects are not fully considered at the GOSCI level, this elimination is critical to secure the reliability of the assignment.

\section{METHOD OF CALCULATION}

We used the Koga, Tatewaki, and Matsuoka (KTM) basis $\operatorname{set}^{13}$ as in the previous MRCISD study, ${ }^{15}$ but this time it was employed as primitive Gaussian-type functions (pGTFs) without contractions. The exponents for the $l_{-}(j=l-1 / 2)$ spinors are used for the $l_{+}(j=l+1 / 2)$ spinors as well. For Gd two $p$ functions of exponents 0.050 and 0.019 (Ref. 19) and two $g$ functions of exponents 5.35 and 2.67 are further added, and for $\mathrm{F}$ two $d$ functions of exponents 3.559 and $0.682,{ }^{19}$ yielding a total of 362 and 817 pGTFs for the large and the small components, respectively. The total basis set is as follows:

\section{Gd: (25s $21 p \quad 16 d \quad 10 f \quad 2 g)$,}

\section{F: $\quad\left(\begin{array}{lll}12 s & 8 p & 2 d\end{array}\right)$.}

We used the uniform nuclear model throughout the paper. All the Hartree-Fock (HF) and GOSCI calculations, based on the Dirac-Coulomb (DC) Hamiltonian, were done with the DIRAC program system. The GOSCI module is an extended version of the COSCI (complete open-shell CI) program $^{20}$ originally implemented to the MOLFDIR program suite $^{21}$ and, as pointed out in the Introduction, we have extended it by a code for the calculation of transition density matrices and transition dipole moments. The transition probability $A_{i j}\left(\mathrm{~s}^{-1}\right)$ is evaluated according to the following formula, ${ }^{22}$ where $\mu_{i j}$ is the norm of transition dipole moment (Debye) and $\bar{\nu}_{i j}$ is the energy difference $\left(\mathrm{cm}^{-1}\right)$ between states $i$ and $j$.

$$
A_{i j}=\frac{8 \pi^{2}}{3 \hbar \varepsilon_{0}}\left|\mu_{i j}\right|^{2} \bar{\nu}_{i j}^{3}=3.137 \times 10^{-7}\left|\mu_{i j}\right|^{2} \bar{\nu}_{i j}^{3} .
$$

The calculations were carried out in $C_{2 v}$ symmetry. However, the spinors are classified according to the projection of total angular momentum $(\omega)$ on the molecular axis and the CI Hamiltonian is explicitly constructed and diagonalized for each block of $\Omega$.

As the active spinors of GOSCI, the 26 molecular spinors, corresponding to 13 Kramers pairs, consisting mainly of the Gd $4 f, 5 d, 6 s$, and $6 p$ atomic spinors were selected. The CI space is generated by a direct product of two spaces, i.e., $(4 f)^{7} \otimes(5 d, 6 s)^{2}$; one is generated by distributing seven electrons in 14 spinors mainly composed of Gd $4 f$ atomic spinors and the other by distributing two elec- trons in 12 spinors mainly composed of Gd $5 d$, and $6 s$, and $6 p$ atomic spinors. This restriction was introduced in order to make the CI calculation feasible by reducing the total number of Slater determinants and is critical because the current GOSCI module stores and keeps the CI matrix in the main memory and diagonalizes it with the in-core algorithm.

The ground state of GdF is $(4 f)^{7}(6 s)^{2}$ and most of its low-lying excited states are $(4 f)^{7}(5 d)^{1}(6 s)^{1}$ and $(4 f)^{7}(5 d)^{2}$ as shown by the experiment of Kaledin et al. ${ }^{7}$ Separating the $(4 f)$ and $(5 d, 6 s)$ manifolds is therefore permissible as a first approximation. However, the ${ }^{8} \Phi_{13 / 2}(4 f)^{8}(6 s)^{1}$ state is expected by their LFT calculations at $2.388 \mathrm{eV}\left(19259 \mathrm{~cm}^{-1}\right)$ above the ground state, ${ }^{7}$ which is not so high. Although the ground state ${ }^{23}$ of the $\mathrm{Gd}$ cation $\left(\mathrm{Gd}^{+}\right)$is ${ }^{10} \mathrm{D}_{5 / 2}$ of the $(4 f)^{7}(5 d)^{1}(6 s)^{1}$ configuration, its first excited state $\left({ }^{8} \mathrm{~F}_{13 / 2}\right)$ of the $(4 f)^{8}(6 s)^{1}$ configuration is observed at $0.991 \mathrm{eV}$ $\left(7992.3 \mathrm{~cm}^{-1}\right)$ above the ground state. ${ }^{23}$ Despite these facts we have chosen to neglect $(4 f)^{8}$ configurations in the present GOSCI calculations. By this separation the total number of Slater determinants becomes 19798 for the case of $\Omega=1 / 2$, for example. Since we are mainly interested in the dipole transitions between the low-lying excited states where $(4 f)^{8}$ does not play an important role, we conclude that the neglect of $(4 f)^{8}$ is reasonable.

In the previous MRCISD study, ${ }^{15}$ an HF/DC spinor set optimized for the neutral GdF molecule was used. However, in the present study, a spinor set obtained from an HF/DC average-configuration $(4 f)^{7}(6 s)^{1}$ of $\mathrm{GdF}^{+}$is used. The reason why we used a cation spinor set is that the SCF procedure for HF/DC did not converge for the neutral system $(4 f)^{7}(6 s)^{2}$. On the other hand, such cation spinor sets gave spectroscopic constants and excitation energies for $\mathrm{LaF}$ (Ref. 24) and CeF (Ref. 25) consistent with experiment.

Vertical excitation energies $\left(T_{v}\right)$ and transition dipole moments are evaluated at the equilibrium internuclear distance $R_{e}=3.7599$ a.u. obtained by GOSCI. To obtain potential energy curves (PECs), we have performed calculations at the six internuclear distances from 3.25 until 4.50 a.u. with a grid spacing of 0.25 a.u. Vibrational constants such as $R_{e}, \omega_{e}$, $\omega_{e} x_{e}$, etc., are obtained from cubic natural spline curves fitted to the GOSCI total energy values. $T_{e}$ (calculated from the potential minima) and $T_{0}$ (calculated from the potential minima $+1 / 2 \hbar \omega)$ are also evaluated. The term value of upper (lower) state is denoted by $T^{\prime}\left(T^{\prime \prime}\right)$ and the transition energy $\left(T^{\prime}-T^{\prime \prime}\right)$ by $\Delta T$. Similarly $\Delta \Omega$ is defined as $\left(\Omega^{\prime}-\Omega^{\prime \prime}\right)$. The state numbers in the full space ( $\mathrm{SN}$ in tables) are ordered according to the $T_{v}$ values. The state number for a given $\Omega$ is denoted by $N$.

\section{RESULTS AND DISCUSSION}

\section{A. Transitions between the ground state and excited states}

\section{The ground state}

At the GOSCI level, the lowest energy state is found to be $\Omega=7 / 2$. The CI total energy is -11374.421964 a.u.. However, as shown in Table I, the energy difference between $\Omega=7 / 2$ and $\Omega=5 / 2,3 / 2,1 / 2$ is less than $0.001 \mathrm{eV}$ $\left(10 \mathrm{~cm}^{-1}\right)$; the small energy differences in $\Omega=7 / 2,5 / 2,3 / 2$, 
TABLE I. The ground state and its near-degenerate states.

\begin{tabular}{ccccc}
\hline \hline $\mathrm{SN}$ & $\Omega$ & $\mathrm{N}$ & $\begin{array}{c}T_{v} \\
(\mathrm{eV})\end{array}$ & $\begin{array}{c}T_{v} \\
\left(\mathrm{~cm}^{-1}\right)\end{array}$ \\
\hline 1 & $7 / 2$ & 1 & 0.0 & 0.0 \\
2 & $5 / 2$ & 1 & 0.000 & 4.0 \\
3 & $3 / 2$ & 1 & 0.001 & 6.7 \\
4 & $1 / 2$ & 1 & 0.001 & 8.1 \\
\hline \hline
\end{tabular}

$1 / 2$ indicate that they all arise from the atomic $(4 f)^{7}{ }^{8} \mathrm{~S}$ configuration. Kaledin et al. ${ }^{7}$ determined the ground state as ${ }^{8} \Sigma^{-}$. The previous HF/DC study by Tatewaki and Matsuoka ${ }^{10}$ as well as our previous MRCISD study ${ }^{15}$ also support $\Omega$ $=7 / 2$. Other researchers ${ }^{8,9,11-14}$ have also assumed $\Omega=7 / 2$. We regard the ground state as $\Omega=7 / 2$ also in this study. It should be noted that the designation $(4 f)^{7}(6 s)^{2}$ is symbolic and the actual $6 s$ molecular spinor has some contributions from $\mathrm{Gd} 5 d$ and $6 p$ atomic spinors.

In the case of $\Omega=7 / 2$, the GOSCI solution of the lowest total energy has a multiconfigurational nature; 79 determinants have CI coefficients whose squares are larger than 0.001 and the largest square among them is only 0.1473 .

Since we are more interested in the excited states than the ground state, we will not analyze in detail the ground state. However, comparing the calculated properties of the ground state with experiment or with the computational results of other researchers would be meaningful to assess the accuracy of our calculation. The calculated dissociation energy $\left(D_{e}\right)$ is $5.31 \mathrm{eV}$ is in reasonable agreement with the experimental value $(6.95 \mathrm{eV}){ }^{26}$ the previous MRCISD value $(5.27 \mathrm{eV}),{ }^{15}$ the $\operatorname{CCSD}(\mathrm{T})$ value $(6.36 \mathrm{eV}),{ }^{14}$ and the CISD $+\mathrm{Q}$ value $(6.24 \mathrm{eV}) .^{12}$ The calculated equilibrium bond length $\left(R_{e}\right) 3.760$ a.u. (1.990 $\left.\AA\right)$ agrees with the experimental value $(1.959 \AA){ }^{7}$ the previous MRCISD value $(1.972 \AA),{ }^{15}$ the $\operatorname{CCSD}(\mathrm{T})$ value $(1.97 \AA),{ }^{14}$ and the CISD $+\mathrm{Q}$ value $(1.963 \AA){ }^{12}$ The $\operatorname{CCSD}(\mathrm{T})$ and $\mathrm{CISD}+\mathrm{Q}$ values are given by scalar relativistic calculations neglecting spinorbit coupling. However, the value of $\omega_{e}\left(565.2 \mathrm{~cm}^{-1}\right)$ is rather small comparing with the experimental value $\left(611 \mathrm{~cm}^{-1}\right)$ cited in Ref. 9. It is also small in comparison with our previous HF/DC value $\left(675 \mathrm{~cm}^{-1}\right)$ (Ref. 13) as well as our MRCISD value $\left(674 \mathrm{~cm}^{-1}\right){ }^{15}$ Although it is a peculiar feature for the valence full-CI-like methods that the calculated $\omega_{e}$ values are small, this discrepancy indicates that the accuracy of the present calculation is at the semiquantitative level due to the insufficient consideration of the electronic correlation effects. Hence we must be careful in analyzing the excited states in subsequent sections and must proceed with the help of the previous MRCISD results. ${ }^{15}$

\section{Excited states around $0.55 \mathrm{eV}$}

Kaledin et al. $^{7}$ found ten forbidden bands around 0.548 $\mathrm{eV}\left(4416 \mathrm{~cm}^{-1}\right)$. We searched states in the range from 0.01 to $0.7 \mathrm{eV}$ and also found ten states. They are listed in Table II with their gross atomic orbital populations (GAOPs). Hereafter atomic spinors are surrounded with square brackets to distinguish them from molecular spinors noted by parentheses. As shown in Table II, the states are concentrated in the energy region from 0.44 to $0.57 \mathrm{eV}$. They are generated mainly by combining $\Omega=7 / 2$ of $(4 f)^{7}$ and $(\Omega=3,2,1)$ of $(5 d)^{1}(6 s)^{1}$. All of them have small transition probabilities with the ground state, which agrees with the fact that the direct transitions from the ground state are not observed experimentally. By comparing the ground state population $[4 f]^{7}[6 s]^{1.5}[5 d]^{0.3}[6 p]^{0.2}$ with the excited state populations $[4 f]^{7}[6 s]^{0.8}[5 d]^{1.1}[6 p]^{0.1}$, one can recognize that these transitions occur from the excitations from $6 s$ to $5 d$ atomic spinors. This is a reason why the transition dipole moments are small. We may also explain this by the lower $(5 d)^{1}(6 s)^{1}$ configurations being tripletlike with respect to the ground state. That the calculated transition energies increase as the $\Omega$ value varies from $5 / 2,3 / 2,1 / 2,1 / 2,3 / 2,5 / 2,7 / 2$, $9 / 2,11 / 2$, to $13 / 2$ agrees well with the LFT calculations of Kaledin et al.

One may doubt the accuracy of the calculated transition dipole moments (probabilities) since the diffuse pGTFs are not included in the basis set. We tried to use the set including the diffuse pGTFs but failed to obtain the converged SCF solutions. We therefore cannot clarify the effects of the diffuse pGTFs for GdF. We found for the other molecule YF

TABLE II. Excited states below $0.55 \mathrm{eV}$.

\begin{tabular}{|c|c|c|c|c|c|c|c|c|c|c|c|c|}
\hline SN & $\Omega$ & $N$ & Population & $\begin{array}{c}T_{0} \\
(\mathrm{eV})\end{array}$ & $\begin{array}{l}T_{0}{ }^{\mathrm{a}} \\
(\mathrm{eV})\end{array}$ & $\begin{array}{c}T_{0}{ }^{\mathrm{a}} \\
\left(\mathrm{cm}^{-1}\right)\end{array}$ & $\begin{array}{l}D_{e}{ }^{\mathrm{b}} \\
(\mathrm{eV})\end{array}$ & $\begin{array}{c}R_{e} \\
\text { (a.u.) }\end{array}$ & $\begin{array}{c}\omega_{e} \\
\left(\mathrm{~cm}^{-1}\right)\end{array}$ & $\begin{array}{c}\omega_{e} x_{e} \\
\left(\mathrm{~cm}^{-1}\right)\end{array}$ & $\begin{array}{l}\text { Tr-mom } \\
\text { (D) }\end{array}$ & $\begin{array}{c}\text { Tr-prob } \\
\left(\mathrm{s}^{-1}\right)\end{array}$ \\
\hline 1 & $7 / 2$ & 1 & {$[4 f]^{7.0}[6 s]^{1.5}[5 d]^{0.3}[6 p]^{0.2}$} & 0.0 & 0.0 & 0 & 5.306 & 3.760 & 565.2 & -5.3 & - & - \\
\hline 5 & $5 / 2$ & 2 & {$[4 f]^{7.0}[6 s]^{0.8}[5 d]^{1.1}[6 p]^{0.1}$} & 0.436 & 0.245 & 1978 & 4.866 & 3.863 & 504.3 & -1.1 & 0.505 & 0.122 \\
\hline 6 & $3 / 2$ & 2 & {$[4 f]^{7.0}[6 s]^{0.8}[5 d]^{1.1}[6 p]^{0.1}$} & 0.448 & 0.263 & 2121 & 4.855 & 3.862 & 504.4 & -1.2 & - & - \\
\hline 7 & $1 / 2$ & 2 & {$[4 f]^{7.0}[6 s]^{0.8}[5 d]^{1.1}[6 p]^{0.1}$} & 0.460 & 0.281 & 2269 & 4.842 & 3.862 & 504.4 & -1.2 & - & - \\
\hline 8 & $1 / 2$ & 3 & {$[4 f]^{7.0}[6 s]^{0.8}[5 d]^{1.1}[6 p]^{0.1}$} & 0.472 & 0.301 & 2426 & 4.830 & 3.861 & 504.5 & -1.2 & - & - \\
\hline 9 & $3 / 2$ & 3 & {$[4 f]^{7.0}[6 s]^{0.8}[5 d]^{1.1}[6 p]^{0.1}$} & 0.485 & 0.321 & 2590 & 4.817 & 3.860 & 504.6 & -1.3 & - & - \\
\hline 10 & $5 / 2$ & 3 & {$[4 f]^{7.0}[6 s]^{0.8}[5 d]^{1.1}[6 p]^{0.1}$} & 0.499 & 0.343 & 2764 & 4.803 & 3.859 & 504.7 & -1.3 & 0.000 & 0.000 \\
\hline 11 & $7 / 2$ & 2 & {$[4 f]^{7.0}[6 s]^{0.8}[5 d]^{1.1}[6 p]^{0.1}$} & 0.513 & 0.366 & 2950 & 4.789 & 3.859 & 504.8 & -1.3 & 0.001 & 0.000 \\
\hline 12 & $9 / 2$ & 1 & {$[4 f]^{7.0}[6 s]^{0.8}[5 d]^{1.1}[6 p]^{0.1}$} & 0.528 & 0.391 & 3150 & 4.834 & 3.858 & 505.0 & -1.4 & 0.003 & 0.000 \\
\hline 13 & $11 / 2$ & 1 & {$[4 f]^{7.0}[6 s]^{0.8}[5 d]^{1.1}[6 p]^{0.1}$} & 0.544 & 0.417 & 3367 & 4.818 & 3.857 & 505.3 & -1.4 & - & - \\
\hline 14 & $13 / 2$ & 1 & {$[4 f]^{7.0}[6 s]^{0.8}[5 d]^{1.1}[6 p]^{0.1}$} & 0.561 & 0.447 & 3608 & 4.850 & 3.856 & 505.6 & -1.5 & - & - \\
\hline
\end{tabular}

${ }^{\mathrm{a}} T_{0}$ values from LFT calculations by Kaledin et al. (Ref. 7).

${ }^{\mathrm{b}}$ Dissociation energy is calculated from $\left\{\mathrm{TE}\left(\mathrm{Gd} ; 4 f^{7} 5 d^{1} 6 s^{29} \mathrm{D}\left(\Omega_{1}\right)-\mathrm{TE}\left(\mathrm{F} ; 2 p^{52} \mathrm{P}\left(\Omega_{2}\right)\right\}_{\Omega=\Omega_{1}+\Omega_{2}}-\mathrm{TE}\left(\mathrm{GdF}(\Omega)\right.\right.\right.$ at respective $\left.R_{e}\right)$.

${ }^{\mathrm{c}}$ The dashes denote forbidden transitions. 
TABLE III. Vertical excitation energies $\left(T_{v}\right)$ in the range from 0.7 to $3.0 \mathrm{eV}$ and the transition dipole moments (entries of which transition moments are larger than $2.5 \mathrm{D}$ are listed in bold type).

\begin{tabular}{|c|c|c|c|c|c|c|c|c|c|c|c|c|c|c|}
\hline SN & $\Omega$ & $\mathrm{N}$ & $\begin{array}{c}T_{v} \\
(\mathrm{eV})\end{array}$ & $\begin{array}{l}\text { Tr-mom } \\
\text { (D) }\end{array}$ & $\mathrm{SN}$ & $\Omega$ & $\mathrm{N}$ & $\begin{array}{c}T_{v} \\
(\mathrm{eV})\end{array}$ & $\begin{array}{l}\text { Tr-mom } \\
\text { (D) }\end{array}$ & SN & $\Omega$ & $N$ & $\begin{array}{c}T_{v} \\
(\mathrm{eV})\end{array}$ & $\begin{array}{l}\text { Tr-mom } \\
\text { (D) }\end{array}$ \\
\hline 15 & $7 / 2$ & 3 & 0.782 & 0.147 & 52 & $9 / 2$ & 6 & 1.763 & 0.034 & 94 & $7 / 2$ & 14 & 2.309 & 0.739 \\
\hline 16 & $5 / 2$ & 4 & 0.796 & 0.113 & 53 & $7 / 2$ & 9 & 1.766 & 0.005 & 95 & $9 / 2$ & 10 & 2.322 & 0.158 \\
\hline 21 & $5 / 2$ & 5 & 0.879 & 0.009 & 54 & $5 / 2$ & 11 & 1.769 & 0.020 & 96 & $5 / 2$ & 19 & 2.406 & 0.770 \\
\hline 22 & $7 / 2$ & 4 & 0.899 & 0.043 & 62 & $5 / 2$ & 12 & 1.848 & 0.505 & 99 & $7 / 2$ & 15 & 2.407 & 0.299 \\
\hline 23 & $9 / 2$ & 2 & 0.922 & 0.184 & 63 & $9 / 2$ & 7 & 1.850 & 0.247 & 102 & $5 / 2$ & 20 & 2.423 & 0.342 \\
\hline 29 & $5 / 2$ & 6 & 1.089 & 0.000 & 64 & $7 / 2$ & 10 & 1.855 & 0.232 & 103 & $7 / 2$ & 16 & 2.424 & 0.238 \\
\hline 30 & $7 / 2$ & 5 & 1.110 & 0.002 & 65 & $7 / 2$ & 11 & 1.858 & 0.308 & 104 & $9 / 2$ & 11 & 2.424 & 0.606 \\
\hline 31 & $9 / 2$ & 3 & 1.131 & 0.003 & 66 & $5 / 2$ & 13 & 1.861 & 0.081 & 106 & $5 / 2$ & 21 & 2.467 & 0.530 \\
\hline 33 & $9 / 2$ & 4 & 1.259 & 0.374 & 74 & $5 / 2$ & 14 & 2.003 & 0.034 & 108 & $7 / 2$ & 17 & 2.499 & 4.537 \\
\hline 34 & $7 / 2$ & 6 & 1.276 & 0.072 & 75 & $5 / 2$ & 15 & 2.019 & 4.534 & 109 & $5 / 2$ & 22 & 2.502 & 0.039 \\
\hline 35 & $5 / 2$ & 7 & 1.287 & 0.115 & 77 & $7 / 2$ & 12 & 2.030 & 0.000 & 115 & $5 / 2$ & 23 & 2.542 & 0.004 \\
\hline 38 & $5 / 2$ & 8 & 1.317 & 0.562 & 81 & $9 / 2$ & 8 & 2.059 & 0.556 & 116 & $7 / 2$ & 18 & 2.550 & 0.084 \\
\hline 43 & $5 / 2$ & 9 & 1.407 & 0.079 & 82 & $5 / 2$ & 16 & 2.061 & 0.374 & 117 & $9 / 2$ & 12 & 2.556 & 0.045 \\
\hline 44 & $7 / 2$ & 7 & 1.424 & 0.102 & 83 & $7 / 2$ & 13 & 2.068 & 0.013 & 123 & $5 / 2$ & 24 & 2.787 & 0.000 \\
\hline 45 & $9 / 2$ & 5 & 1.446 & 0.142 & 84 & $9 / 2$ & 9 & 2.075 & 4.850 & 124 & $7 / 2$ & 19 & 2.805 & 0.000 \\
\hline 46 & $7 / 2$ & 8 & 1.625 & 0.164 & 88 & $5 / 2$ & 17 & 2.180 & 1.126 & 125 & $9 / 2$ & 13 & 2.826 & 0.007 \\
\hline 47 & $5 / 2$ & 10 & 1.659 & 0.092 & 93 & $5 / 2$ & 18 & 2.301 & 0.194 & & & & & \\
\hline
\end{tabular}

that the sets with the diffuse pGTFs bring $50 \%$ changes in the ground state dipole moment than the set without them. The effects of the diffuse functions are not so large as we worried. Moreover, since we are concerned whether the state is observed or not, the relative values of the transition probabilities are important. We may find our discussion is quite safe if we compare the transition probabilities in Tables II with those in Table IV.

In the previous MRCISD study, ${ }^{15}$ we proposed three candidates for the states around $0.55 \mathrm{eV}$. The most promising one was $\Omega=13 / 2,(4 f)^{7}(5 d)^{1}(6 s)^{1}$ of $T_{0}=0.582 \mathrm{eV}$, the others being $\Omega=5 / 2$ of $T_{0}=0.494 \mathrm{eV}$ and $\Omega=9 / 2$ of $T_{0}$ $=0.652 \mathrm{eV}$. All these three states are included in Table II and are retained as candidates even after the present refinement. The present GOSCI calculation gives $T_{0}=0.561 \mathrm{eV}$ for $\Omega$ $=13 / 2$. This value of $T_{0}$ is close to the previous MRCISD result of $0.582 \mathrm{eV}$.

\section{The $[15.8]$ state}

Kaledin et $a .^{7}$ observed a strong band of $1.956 \mathrm{eV}$ (15 $776.9 \mathrm{~cm}^{-1}$ ) and designated it as [15.8]. They found another strong band of $2.264 \mathrm{eV}\left(18261.9 \mathrm{~cm}^{-1}\right)$ and designated it as [18.3]. Since these bands are transitions to the $\Omega=7 / 2$ ground state, we searched CI solutions of $\Omega=5 / 2$,
$7 / 2$, or $9 / 2$. There are 50 states whose vertical transition energies $\left(T_{v}\right)$ are in the range from 0.7 to $3.0 \mathrm{eV}$ and they are listed in Table III with the transition dipole moments. Among them only three states have transition dipole moments greater than 2.5 D. These three states are listed in bold type in Table III and their details are listed in Table IV. Their PECs are shown in Fig. 1. The calculated values of $T_{0}$ are $2.020 \mathrm{eV}(\Omega=5 / 2), 2.073 \mathrm{eV}(\Omega=9 / 2)$, and $2.434 \mathrm{eV}(\Omega$ $=7 / 2$ ), respectively. From the energetical point of view, the lower two states should be considered as the [15.8] state and the uppermost state as the [18.3] state. The large values of $\omega_{e} x_{e}$ in Table IV are due to the shallow double minimum on their PECs in Fig. 1.

The populations of the $\Omega=5 / 2$ and $\Omega=9 / 2$ states are $[4 f]^{7.0}[6 s]^{0.5}[5 d]^{0.9}[6 p]^{0.6}$ and $[4 f]^{7.0}[6 s]^{0.4}[5 d]^{0.9}[6 p]^{0.6}$, respectively. The contributions from the atomic $6 p$ spinors are significant. Comparing these with the ground state population $[4 f]^{7}[6 s]^{1.5}[5 d]^{0.3}[6 p]^{0.2}$, we recognize that the $[15.8]$ state is described mainly by a transition from the atomic $6 s$ to atomic $6 p$ and $5 d$ spinors.

In the previous MRCISD study, we identified the $\Omega$ $=7 / 2$ as [15.8]. However, we should have regarded the $\Omega$ $=5 / 2$ state of $T_{0}=1.954 \mathrm{eV}$ and the $\Omega=9 / 2$ state of $T_{0}$ $=1.972 \mathrm{eV}$ given by MRCISD as the [15.8] state straightforwardly. The electronic configuration $(4 f)^{7}\left(5 d_{-}+5 d_{+}\right)^{1}\left(6 s_{+}\right)^{1}$

TABLE IV. Candidates for the [15.8] and [18.3] states.

\begin{tabular}{|c|c|c|c|c|c|c|c|c|c|c|c|c|c|}
\hline $\mathrm{SN}$ & $\Omega$ & $N$ & Population & $\begin{array}{c}T_{0} \\
(\mathrm{eV})\end{array}$ & $\begin{array}{l}T_{0}{ }^{\mathrm{a}} \\
(\mathrm{eV})\end{array}$ & $\begin{array}{l}T_{0}{ }^{\mathrm{b}} \\
(\mathrm{eV})\end{array}$ & $\begin{array}{c}T_{0}{ }^{\mathrm{b}} \\
\left(\mathrm{cm}^{-1}\right)\end{array}$ & $\begin{array}{l}D_{e}{ }^{\mathrm{c}} \\
(\mathrm{eV})\end{array}$ & $\begin{array}{c}R_{e} \\
\text { (a.u.) }\end{array}$ & $\begin{array}{c}\omega_{e} \\
\left(\mathrm{~cm}^{-1}\right)\end{array}$ & $\begin{array}{c}\omega_{e} x_{e} \\
\left(\mathrm{~cm}^{-1}\right)\end{array}$ & $\begin{array}{l}\text { Tr-mom } \\
\text { (D) }\end{array}$ & $\begin{array}{c}\text { Tr-prob } \\
\left(\mathrm{s}^{-1}\right)\end{array}$ \\
\hline 1 & $7 / 2$ & 1 & {$[4 f]^{7.0}[6 s]^{1.5}[5 d]^{0.3}[6 p]^{0.2}$} & 0.0 & 0.0 & 0.0 & 0 & 5.306 & 3.760 & 565.2 & -5.3 & - & - \\
\hline 75 & $5 / 2$ & 15 & {$[4 f]^{7.0}[6 s]^{0.5}[5 d]^{0.9}[6 p]^{0.6}$} & 2.020 & 1.954 & 1.956 & 15776.9 & 3.287 & 3.775 & 691.6 & 237.5 & 4.534 & $2.79 \mathrm{E}+07$ \\
\hline 84 & $9 / 2$ & 9 & {$[4 f]^{7.0}[6 s]^{0.4}[5 d]^{0.9}[6 p]^{0.6}$} & 2.073 & 1.972 & 1.956 & 15776.9 & 3.291 & 3.782 & 656.1 & 242.4 & 4.850 & $3.46 \mathrm{E}+07$ \\
\hline 108 & $7 / 2$ & 17 & {$[4 f]^{7.0}[6 s]^{0.6}[5 d]^{0.9}[6 p]^{0.5}$} & 2.434 & 2.548 & 2.264 & 18261.9 & 2.865 & 4.158 & 516.3 & 115.7 & 4.537 & $5.29 \mathrm{E}+07$ \\
\hline
\end{tabular}

${ }^{\mathrm{a}} T_{0}$ values obtained from our previous MRCISD calculations (Ref. 15).

${ }^{\mathrm{b}}$ Expt. (Ref. 7).

${ }^{\mathrm{c}}$ Dissociation energy is calculated from $\left\{\mathrm{TE}\left(\mathrm{Gd} ; 4 f^{7} 5 d^{1} 6 s^{29} \mathrm{D}\left(\Omega_{1}\right)-\mathrm{TE}\left(\mathrm{F} ; 2 p^{52} \mathrm{P}\left(\Omega_{2}\right)\right\}_{\Omega=\Omega_{1}+\Omega_{2}}-\mathrm{TE}\left(\mathrm{GdF}(\Omega)\right.\right.\right.$ at respective $\left.R_{e}\right)$. 


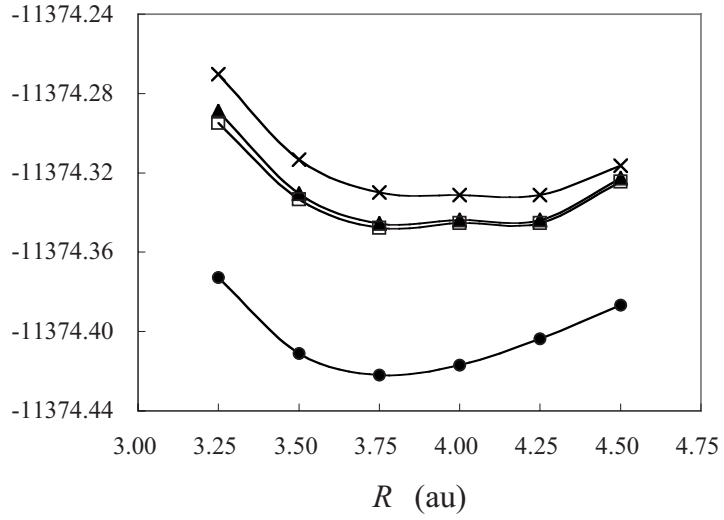

FIG. 1. PECs of the ground state and two candidate states for the [15.8] state and one for the [18.3] state. Cross: $(\Omega=7 / 2, N=17)$. A candidate state for [18.3]. Solid triangle: $(\Omega=9 / 2, N=9)$. A candidate state for [15.8]. Open rectangle: $(\Omega=5 / 2, N=15)$. A candidate state for [15.8]. Solid circle: $(\Omega$ $=7 / 2, N=1)$. The ground state.

which both states was considered to have is consistent with the present characterization. Thus, it is quite reasonable to regard these two states having close energies as the [15.8] states.

The double-minimum PECs shown in Fig. 1 can be ascribed to the mixing of two configuration groups of $(4 f)^{7}(5 d)^{1}(6 s)^{1}$ and $(4 f)^{7}(5 d)^{2}$. The details are given in the Appendix.

\section{The [18.3] state}

The $\Omega=7 / 2$ state of $T_{0}=2.434 \mathrm{eV}$ in Table IV has a population of $[4 f]^{7.0}[6 s]^{0.6}[5 d]^{0.9}[6 p]^{0.5}$. This is consistent with the assignment of Kaledin et al. ${ }^{7}$ The present value of $T_{0}$ is somewhat larger than the experimental value of 2.264 $\mathrm{eV}$, but if we consider the fact that the $T_{0}$ value $(2.548 \mathrm{eV})$ of the corresponding $\Omega=7 / 2$ in the previous MRCISD study is the same as the present value, this discrepancy of $0.2 \mathrm{eV}$ is within a permissible range. We find no other strong transitions in this energy region, and the $\Omega=7 / 2$ state of Table IV should therefore be regarded as the [18.3] state.

As shown in Fig. 1, the double-minimum potential is diminished. This can be ascribed to the larger weight of the configuration group of $(4 f)^{7}(5 d)^{1}(6 s)^{1}$ in the [18.3] state. (See Appendix) The diminishing of the double-minimum in the PEC gives $\omega_{e} x_{e}$ smaller than those of the [15.8] state as shown in Table IV.

\section{B. Transitions between excited states}

Generally speaking, there are three cases for the transitions between the excited states according to the selection rule, i.e., $\Delta \Omega= \pm 1$ and 0 . Kaledin et al. ${ }^{7}$ observed $\Delta \Omega=$ +1 transitions in the near-infrared region and $\Delta \Omega=0$ transitions in the visible region, but they reported nothing about the $\Delta \Omega=-1$ case. Let us start the discussion from the $\Delta \Omega$ $=+1$ case.

\section{1. $\Delta \Omega=+1$ (near-infrared region)}

Kaledin et al. identified six bands in the near-infrared region $\left(\sim 13666 \mathrm{~cm}^{-1}\right)$ as the transitions of $\Delta \Omega=+1$ as listed in the 11th and 12th columns of Table V. In this energy region we searched $\Delta \Omega=+1$ transitions whose calculated transition dipole moments are greater than $50 \%$ of the maximum one $(2.5 \mathrm{D})$. We find ten transitions. We classified them into two groups so that $\Delta T_{0}$ decreases by about $0.01 \mathrm{eV}$ with decreasing $\Omega^{\prime \prime}$. We call these groups sequences from now on. These two sequences are listed in Table $\mathrm{V}$. The first sequence begins from $\Delta T_{0}=1.560 \mathrm{eV}$ and the second sequence from $1.894 \mathrm{eV}$. The energy gap between them is as large as 0.311 $\mathrm{eV}$. In both sequences, the upper states have a population of $[4 f]^{7.0}[5 d]^{1.4}[6 p]^{0.5}$. It should be noted that all the lower states here are the low-lying excited states which appear as the entries of Table II with populations of $[4 \mathrm{f}]^{7.0}[5 \mathrm{~d}]^{1.1}[6 \mathrm{~s}]^{0.8}[6 \mathrm{p}]^{0.1}$.

The first member of the first sequence is a transition from the first $\Omega=15 / 2$ state to the first $\Omega=13 / 2$ state. The first $\Omega=15 / 2$ state is located $2.121 \mathrm{eV}$ above the ground state and the first $\Omega=13 / 2$ state $0.561 \mathrm{eV}\left(T_{0}\right)$ above the ground state. Since the corresponding experimental $\Delta T_{0}$ value is $1.732 \mathrm{eV}$, the calculated $\Delta T_{0}$ value $(1.560 \mathrm{eV})$ is a little smaller than the experimental value. The calculated transition energy decreases by about $0.01 \mathrm{eV}$ as $\Omega^{\prime \prime}$ decreases

TABLE V. Transitions between the excited states $(\Delta \Omega=+1)$.

\begin{tabular}{|c|c|c|c|c|c|c|c|c|c|c|c|c|c|c|c|c|}
\hline $\mathrm{SN}^{\prime}$ & $\Omega^{\prime}$ & $N^{\prime}$ & $\mathrm{SN}^{\prime \prime}$ & $\Omega^{\prime \prime}$ & $N^{\prime \prime}$ & Population & $\begin{array}{c}T_{0}^{\prime} \\
(\mathrm{eV})\end{array}$ & $\begin{array}{c}T_{0}^{\prime \prime} \\
(\mathrm{eV})\end{array}$ & $\begin{array}{l}\Delta T_{0} \\
(\mathrm{eV})\end{array}$ & $\begin{array}{l}\Delta T_{0}{ }^{\mathrm{a}} \\
(\mathrm{eV})\end{array}$ & $\begin{array}{l}\Delta T_{0}{ }^{\mathrm{a}} \\
\left(\mathrm{cm}^{-1}\right)\end{array}$ & $\begin{array}{c}R_{e} \\
\text { (a.u.) }\end{array}$ & $\begin{array}{c}\omega_{e} \\
\left(\mathrm{~cm}^{-1}\right)\end{array}$ & $\begin{array}{c}\omega_{e} x_{e} \\
\left(\mathrm{~cm}^{-1}\right)\end{array}$ & $\begin{array}{l}\text { Tr-mom } \\
\text { (D) }\end{array}$ & $\begin{array}{c}\text { Tr-prob } \\
\left(\mathrm{s}^{-1}\right)\left(\times 10^{+07}\right)\end{array}$ \\
\hline \multicolumn{17}{|c|}{ Seq-1 } \\
\hline 87 & $15 / 2$ & 1 & 14 & $13 / 2$ & 1 & {$[4 f]^{7.0}[5 d]^{1.4}[6 p]^{0.5}$} & 2.121 & 0.561 & 1.560 & 1.732 & 13973 & 3.894 & 483.0 & 0.3 & 4.882 & 0.93 \\
\hline 86 & $13 / 2$ & 2 & 13 & $11 / 2$ & 1 & {$[4 f]^{7.0}[5 d]^{1.4}[6 p]^{0.5}$} & 2.083 & 0.544 & 1.539 & 1.719 & 13861 & 3.893 & 483.4 & 0.3 & 4.861 & 1.47 \\
\hline 85 & $11 / 2$ & 5 & 12 & $9 / 2$ & 1 & {$[4 f]^{7.0}[5 d]^{1.4}[6 p]^{0.6}$} & 2.048 & 0.528 & 1.520 & 1.706 & 13759 & 3.893 & 483.9 & 0.3 & 4.850 & 1.41 \\
\hline 81 & $9 / 2$ & 8 & 11 & $7 / 2$ & 2 & {$[4 f]^{7.0}[5 d]^{1.4}[6 p]^{0.6}$} & 2.019 & 0.513 & 1.506 & 1.694 & 13667 & 3.901 & 456.7 & -0.6 & 4.811 & 1.34 \\
\hline 77 & $7 / 2$ & 12 & 10 & $5 / 2$ & 3 & {$[4 f]^{7.0}[5 d]^{1.4}[6 p]^{0.6}$} & 1.989 & 0.499 & 1.490 & 1.683 & 13578 & 3.896 & 473.8 & -1.7 & 4.826 & 1.30 \\
\hline 74 & $5 / 2$ & 14 & 9 & $3 / 2$ & 3 & {$[4 f]^{7.0}[5 d]^{1.4}[6 p]^{0.6}$} & 1.962 & 0.485 & 1.477 & 1.673 & 13497 & 3.901 & 486.0 & 1.0 & 4.822 & 1.27 \\
\hline 73 & $3 / 2$ & 18 & 8 & $1 / 2$ & 3 & {$[4 f]^{7.0}[5 d]^{1.4}[6 p]^{0.6}$} & 1.932 & 0.472 & 1.460 & - & - & 3.897 & 558.7 & 4.1 & 4.808 & 1.23 \\
\hline \multicolumn{17}{|c|}{ Seq-2 } \\
\hline 99 & $7 / 2$ & 15 & 5 & $5 / 2$ & 2 & {$[4 f]^{7.0}[5 d]^{1.4}[6 p]^{0.6}$} & 2.330 & 0.436 & 1.894 & - & - & 3.937 & 502.4 & 2.3 & 4.708 & 2.68 \\
\hline 96 & $5 / 2$ & 19 & 6 & $3 / 2$ & 2 & {$[4 f]^{7.0}[5 d]^{1.4}[6 p]^{0.6}$} & 2.330 & 0.448 & 1.882 & - & - & 3.939 & 495.3 & 1.9 & 4.096 & 1.99 \\
\hline 97 & $3 / 2$ & 23 & 7 & $1 / 2$ & 2 & {$[4 f]^{7.0}[5 d]^{1.4}[6 p]^{0.6}$} & 2.331 & 0.460 & 1.871 & - & - & 3.943 & 475.3 & 1.5 & 3.754 & 1.64 \\
\hline
\end{tabular}

${ }^{\mathrm{a}}$ Expt. (Ref. 7). 
TABLE VI. Transitions between the excited states $(\Delta \Omega=-1)$.

\begin{tabular}{|c|c|c|c|c|c|c|c|c|c|c|c|c|c|c|}
\hline $\mathrm{SN}^{\prime}$ & $\Omega^{\prime}$ & $N^{\prime}$ & $\mathrm{SN}^{\prime \prime}$ & $\Omega^{\prime \prime}$ & $N^{\prime \prime}$ & Population & $\begin{array}{c}T_{0}^{\prime} \\
(\mathrm{eV})\end{array}$ & $\begin{array}{c}T_{0}^{\prime \prime} \\
(\mathrm{eV})\end{array}$ & $\begin{array}{l}\Delta T_{0} \\
(\mathrm{eV})\end{array}$ & $\begin{array}{c}R_{e} \\
\text { (a.u.) }\end{array}$ & $\begin{array}{c}\omega_{e} \\
\left(\mathrm{~cm}^{-1}\right)\end{array}$ & $\begin{array}{c}\Omega_{e} x_{e} \\
\left(\mathrm{~cm}^{-1}\right)\end{array}$ & $\begin{array}{l}\text { Tr-mom } \\
\text { (D) }\end{array}$ & $\begin{array}{c}\text { Tr-prob } \\
\left(\mathrm{s}^{-1}\right)\left(\times 10^{+07}\right)\end{array}$ \\
\hline \multicolumn{15}{|c|}{ Seq-1 } \\
\hline 105 & $11 / 2$ & 6 & 14 & $13 / 2$ & 1 & {$[4 f]^{7.0}[6 s]^{0.0}[5 d]^{1.4}[6 p]^{0.6}$} & 2.347 & 0.561 & 1.786 & 3.945 & 474.8 & 1.8 & 5.086 & 2.65 \\
\hline 104 & $9 / 2$ & 11 & 13 & $11 / 2$ & 1 & {$[4 f]^{7.0}[6 s]^{0.0}[5 d]^{1.4}[6 p]^{0.6}$} & 2.348 & 0.544 & 1.804 & 3.941 & 476.4 & 1.2 & 4.774 & 2.39 \\
\hline 103 & $7 / 2$ & 16 & 12 & $9 / 2$ & 1 & {$[4 f]^{7.0}[6 s]^{0.0}[5 d]^{1.4}[6 p]^{0.6}$} & 2.350 & 0.528 & 1.822 & 3.938 & 478.2 & 1.2 & 4.282 & 1.97 \\
\hline 102 & $5 / 2$ & 20 & 11 & $7 / 2$ & 2 & {$[4 f]^{7.0}[6 s]^{0.0}[5 d]^{1.4}[6 p]^{0.6}$} & 2.348 & 0.513 & 1.835 & 3.937 & 486.8 & 1.6 & 3.966 & 1.73 \\
\hline 101 & $3 / 2$ & 24 & 10 & $5 / 2$ & 3 & {$[4 f]^{7.0}[6 s]^{0.1}[5 d]^{1.4}[6 p]^{0.6}$} & 2.348 & 0.499 & 1.849 & 3.936 & 484.2 & 1.3 & 3.589 & 1.44 \\
\hline 98 & $1 / 2$ & 24 & 9 & $3 / 2$ & 3 & {$[4 f]^{7.0}[6 s]^{0.1}[5 d]^{1.4}[6 p]^{0.6}$} & 2.331 & 0.485 & 1.846 & 3.937 & 505.8 & 2.4 & 2.893 & 0.94 \\
\hline 100 & $1 / 2$ & 25 & 9 & $3 / 2$ & 3 & {$[4 f]^{7.0}[6 s]^{0.1}[5 d]^{1.4}[6 p]^{0.6}$} & 2.317 & 0.485 & 1.832 & 3.936 & 479.3 & 0.7 & 3.099 & 1.10 \\
\hline \multicolumn{15}{|c|}{ Seq-2 } \\
\hline 70 & $3 / 2$ & 17 & 5 & $5 / 2$ & 2 & {$[4 f]^{7.0}[6 s]^{0.1}[5 d]^{1.4}[6 p]^{0.5}$} & 1.891 & 0.436 & 1.455 & 3.853 & 557.2 & -0.7 & 4.616 & 1.07 \\
\hline 71 & $1 / 2$ & 18 & 6 & $3 / 2$ & 2 & {$[4 f]^{7.0}[6 s]^{0.1}[5 d]^{1.4}[6 p]^{0.6}$} & 1.899 & 0.448 & 1.451 & 3.873 & 556.3 & -0.9 & 4.708 & 1.13 \\
\hline
\end{tabular}

by 1 . This energetics of this sequence agrees well with the observed features. (See the column termed ${ }^{\prime 10} \Phi_{\Omega+1}-\mathrm{a}{ }^{10} \Delta_{\Omega}$ Transition $\nu^{\text {Exp." }}$ in Table IX of Ref. 7.)

The first member of the second sequence is a transition from the fifteenth $\Omega=7 / 2$ state to the second $\Omega=5 / 2$ state. The 15 th $\Omega=7 / 2$ state and the second $\Omega=5 / 2$ state are located 2.330 and $0.436 \mathrm{eV}$ above the ground state, respectively. Since the calculated transition energies are rather large to be considered as the near-infrared energy region, we exclude this second sequence from the candidates for the nearinfrared bands. Kaledin et al. did not report these transitions in the visible region.

\section{2. $\Delta \Omega=-1$}

In the same manner as in the preceding section, we search $\Delta \Omega=-1$ transitions whose transition dipole moment is larger than $2.5 \mathrm{D}$. We find nine transitions. They are listed in Table VI. We classify them into two sequences. The first sequence begins at $\Delta T_{0}=1.786 \mathrm{eV}$ and the second sequence at $\Delta T_{0}=1.455 \mathrm{eV}$. In the first sequence $\Delta T_{0}$ increases as $\Omega^{\prime \prime}$ decreases. Reversely, in the second sequence $\Delta T_{0}$ decreases. The energy gap between them is as large as $0.331 \mathrm{eV}$. All the lower states here are the low-lying excited states which ap- pear in Table II. The large transition probabilities suggest the existence of strong bands, but Kaledin et al. ${ }^{7}$ reported no such observations.

\section{3. $\Delta \Omega=0$ (visible region)}

Kaledin et $a .^{7}$ observed five transitions between the excited states in the visible region (14 389-17 075 $\mathrm{cm}^{-1}$ ) They assigned them as ${ }^{10} \Delta\left((4 f)^{7}(5 d)^{2}\right)$ $-a^{10} \Delta\left((4 f)^{7}(5 d)^{1}(6 s)^{1}\right)$ of $\Delta \Omega=0$. However, as they admit that their assignment is tentative, their assignment has some uncertainties. As listed in the column termed $"{ }^{10} \Delta \Omega$ $-a^{10} \Delta \Omega$ transition $\nu^{\text {exp." }}$ in Table IX of Ref. 7, the observed transition energies are $2.117 \mathrm{eV}\left(17075 \mathrm{~cm}^{-1}, \Omega^{\prime \prime}=5 / 2\right)$, $2.106 \mathrm{eV} \quad\left(16985 \mathrm{~cm}^{-1}, \Omega^{\prime \prime}=3 / 2\right)$, and $2.100 \mathrm{eV}$ $\left(16937 \mathrm{~cm}^{-1}, \Omega^{\prime \prime}=1 / 2\right), 1.805 \mathrm{eV}\left(14559 \mathrm{~cm}^{-1}, \Omega^{\prime \prime}=\right.$ $-3 / 2)$, and $1.784 \mathrm{eV}\left(14389 \mathrm{~cm}^{-1}, \Omega^{\prime \prime}=-5 / 2\right)$. The former three and the latter two form two sequences.

We have searched transitions of large transition dipole moments and find nine transitions which are listed in Table VII. In all the cases, the upper states have a population of $[4 f]^{7.0}[6 s]^{0.0}[5 d]^{1.4}[6 p]^{0.5}$. We classify the transitions into two sequences. The first sequence starts at $\Delta T_{0}=1.905 \mathrm{eV}$ $\Omega^{\prime \prime}=13 / 2$ and the second sequence starts at $\Delta T_{0}=1.944 \mathrm{eV}$ $\left(\Omega^{\prime \prime}=5 / 2\right)$. In the first sequence $\Delta T_{0}$ increases as $\Omega^{\prime \prime}$ de-

TABLE VII. Transitions between the excited states $(\Delta \Omega=0)$

\begin{tabular}{|c|c|c|c|c|c|c|c|c|c|c|c|c|c|c|c|}
\hline $\mathrm{SN}^{\prime}$ & $\Omega^{\prime}$ & $N^{\prime}$ & $\mathrm{SN}^{\prime \prime}$ & $N^{\prime \prime}$ & Population & $\begin{array}{c}T_{0}^{\prime} \\
(\mathrm{eV})\end{array}$ & $\begin{array}{c}T_{0}^{\prime \prime} \\
(\mathrm{eV})\end{array}$ & $\begin{array}{l}\Delta T_{0} \\
(\mathrm{eV})\end{array}$ & $\begin{array}{c}\Delta T_{0}{ }^{\mathrm{a}} \\
(\mathrm{eV})\end{array}$ & $\begin{array}{c}\Delta T_{0}{ }^{\mathrm{a}} \\
\left(\mathrm{cm}^{-1}\right)\end{array}$ & $\begin{array}{c}R_{e} \\
\text { (a.u.) }\end{array}$ & $\begin{array}{c}\omega_{e} \\
\left(\mathrm{~cm}^{-1}\right)\end{array}$ & $\begin{array}{c}\omega_{e} x_{e} \\
\left(\mathrm{~cm}^{-1}\right)\end{array}$ & $\begin{array}{l}\text { Tr-om } \\
\text { (D) }\end{array}$ & $\begin{array}{c}\text { Tr-prob } \\
\left(\mathrm{s}^{-1}\right)\left(\times 10^{+07}\right)\end{array}$ \\
\hline \multicolumn{16}{|c|}{ Seq-1 } \\
\hline 118 & $13 / 2$ & 3 & 14 & 1 & {$[4 f]^{7.0}[6 s]^{0.0}[5 d]^{1.4}[6 p]^{0.5}$} & 2.466 & 0.561 & 1.905 & $-(1.977)$ & $-(15942)$ & 3.958 & 475.7 & 2.0 & 4.258 & 2.29 \\
\hline 119 & $11 / 2$ & 7 & 13 & 1 & {$[4 f]^{7.0}[6 s]^{0.0}[5 d]^{1.4}[6 p]^{0.5}$} & 2.468 & 0.544 & 1.924 & $-(2.017)$ & $-(16271)$ & 3.956 & 476.9 & 1.9 & 4.113 & 2.19 \\
\hline 117 & $9 / 2$ & 12 & 12 & 1 & {$[4 f]^{7.0}[6 s]^{0.0}[5 d]^{1.4}[6 p]^{0.5}$} & 2.466 & 0.528 & 1.938 & $-(2.047)$ & $-(16513)$ & 3.954 & 478.2 & 1.9 & 4.016 & 2.13 \\
\hline 116 & $7 / 2$ & 18 & 11 & 2 & {$[4 f]^{7.0}[6 s]^{0.0}[5 d]^{1.4}[6 p]^{0.5}$} & 2.467 & 0.513 & 1.954 & $-(2.070)$ & $-(16699)$ & 3.935 & 544.6 & 3.0 & 3.944 & 2.08 \\
\hline 115 & $5 / 2$ & 23 & 10 & 3 & {$[4 f]^{7.0}[6 s]^{0.0}[5 d]^{1.4}[6 p]^{0.5}$} & 2.467 & 0.499 & 1.968 & $2.117(2.089)$ & $17075(16846)$ & 3.929 & 533.7 & 2.3 & 3.887 & 2.04 \\
\hline 114 & $3 / 2$ & 27 & 9 & 3 & {$[4 f]^{7.0}[6 s]^{0.1}[5 d]^{1.4}[6 p]^{0.5}$} & 2.465 & 0.485 & 1.980 & $2.106(2.104)$ & $16985(16970)$ & 3.918 & 526.8 & 1.6 & 3.835 & 1.99 \\
\hline 110 & $1 / 2$ & 26 & 7 & 2 & {$[4 f]^{7.0}[6 s]^{0.1}[5 d]^{1.4}[6 p]^{0.5}$} & 2.416 & 0.460 & 1.956 & $2.100(2.036)$ & $16937(16424)$ & 3.965 & 470.4 & 2.5 & 3.399 & 1.56 \\
\hline \multicolumn{16}{|c|}{ Seq-2 } \\
\hline 106 & $5 / 2$ & 21 & 5 & 2 & {$[4 f]^{7.0}[6 s]^{0.1}[5 d]^{1.4}[6 p]^{0.5}$} & 2.380 & 0.436 & 1.944 & 2.117 & 17075 & 3.961 & 467.4 & -1.1 & 3.928 & 2.04 \\
\hline 107 & $3 / 2$ & 25 & 6 & 2 & {$[4 f]^{7.0}[6 s]^{0.1}[5 d]^{1.4}[6 p]^{0.5}$} & 2.400 & 0.448 & 1.952 & 2.106 & 16985 & 3.965 & 469.0 & 0.9 & 3.837 & 1.97 \\
\hline
\end{tabular}

${ }^{a}$ Expt. (Ref. 7). The numbers in parentheses denote the $T_{0}$ values obtained from LFT calculations by Kaledin $e t$ al. 
creases with an exception at $\Omega^{\prime \prime}=1 / 2$. The remaining terms are gathered into the second sequence. These two sequences lie overlapped in energy; there is no energy gap between them. This point is apparently different from the cases of $\Delta \Omega= \pm 1$. Thus, the reason for the classification is not strong. The third $\Omega^{\prime}=13 / 2$ state is located $2.446 \mathrm{eV}$ above the ground state. And the $21 \mathrm{st} \Omega^{\prime}=5 / 2$ state is located 2.380 $\mathrm{eV}$ above the ground state.

As shown in Table VII, the calculated $\Delta T_{0}$ values of the higher members of the first sequence are close to the observed values. While our calculated $\Delta T_{0}$ values increase in the order $\Omega^{\prime \prime}=1 / 2,5 / 2$, and $3 / 2$, the observed ones increase in the order $\Omega^{\prime \prime}=1 / 2,3 / 2$, and $5 / 2$. Kaledin et al. calculated $\Delta T_{0}$ with the LFT method and their values are listed in parentheses in Table VII. LFT predicts the same order as the present work not only for the range of $\Omega^{\prime \prime}(1 / 2,3 / 2,5 / 2)$ but also for all the $\Omega^{\prime \prime}$ states composing the first sequence. Kaledin et al. gave two other experimental $\Delta T_{0}$ values (1.805, $1.784 \mathrm{eV}$ ) for $\Omega^{\prime \prime}=-5 / 2$ and $-3 / 2$ (the second sequences), but we cannot find calculated values corresponding to them. Thus, these two experimental values are not listed in Table VII.

The calculated second sequence consists of only two members, but they give $\Delta T_{0}$ close to those of the first experimental sequences. In fact the $\Delta T_{0}$ value $(1.944 \mathrm{eV})$ for $\Omega^{\prime \prime}$ $=5 / 2$ is close to the experimental $\Delta T_{0}$ value $(2.117 \mathrm{eV})$ as shown in Table VII.

The energy gap between the two experimental sequences is as large as $0.295 \mathrm{eV}(=2.100-1.805 \mathrm{eV})$. This characteristic is not found in the calculated transition energies. We will discuss this point in more detail in Sec. III B 4.

In the previous MRCISD study, the $\Omega^{\prime \prime}=9 / 2$ state was considered as the most promising candidate. The calculated transition energy $\left(\Delta T_{0}\right)$ was $2.141 \mathrm{eV}$. And the upper and lower states were located 2.793 and $0.652 \mathrm{eV}$ above the ground state, respectively. This $\Delta T_{0}$ value is close to the present $\Delta T_{0}$ value $(1.938 \mathrm{eV})$ for $\Omega^{\prime \prime}=9 / 2$ in the first sequences. The previous result seems not to be in contradiction to the present result.

\section{Discussion}

As described in Sec. III B 3, the observed $\Delta T_{0}$ values for $\Delta \Omega=0$ are close to our calculated values, but their order according to $\Omega$ values does not match ours. Their two observed values $(1.805,1.784 \mathrm{eV})$ do not fit to our values. The present calculations and the LFT calculations by Kaledin et $a .^{7}$ both demonstrate that there are more bands than found in the experiment. On the other hand, concerning the $\Delta \Omega=$ -1 transitions, strong bands are expected from the present calculations, while Kaledin et al. reported nothing about the $\Delta \Omega=-1$ case. Although there is an energy gap as large as $0.301 \mathrm{eV}$ in the observed bands for $\Delta \Omega=0$, such a gap is not found in the calculated transition energies of $\Delta \Omega=0$. Instead there is an energy gap of $0.331 \mathrm{eV}$ for the calculated transition energies of $\Delta \Omega=-1$.

These discrepancies seem to suggest that the $\Delta T_{0}$ values (in Table VII) which Kaledin et al. assigned as the $\Delta \Omega=0$ case are values for $\Delta \Omega=-1$. If this is true, the energy order will match the order of the calculated $\Delta T_{0}$ values in Table
VI. Namely, the members of the first sequence of $\Delta \Omega=-1$ at $\Delta T_{0}=1.849,1.846$, and $1.832 \mathrm{eV}$ in Table VI will correspond to the states observed at $\Delta T_{0}=2.117,2.106$, and $2.100 \mathrm{eV}$ of $\Delta \Omega=0$ in Table VII. (Here we assign the observed $\Delta T_{0}$ $=2.100 \mathrm{eV}$ to the $\Omega^{\prime \prime}=3 / 2$ state in $\Delta \Omega=-1$ rather than to $\Omega^{\prime \prime}=1 / 2$.) Likewise the second sequence $\left(\Delta T_{0}=1.455 \mathrm{eV}\right.$ and $1.451 \mathrm{eV}$ ) in Table VI to the observed transition energies (1.784 and $1.805 \mathrm{eV}$ ) of $\Delta \Omega=0$. The large energy gap between the first and second sequences found in our calculations would then be consistent with experiment, and thus a part of the inconsistencies would be resolved.

However, the problem that the present calculations and the LFT calculations by Kaledin et al. both give more bands than the observation still remains unsettled. The remaining inconsistencies need to be investigated further. Electron correlation calculations based on the multireference perturbation theory ${ }^{27,28}$ would be necessary for further theoretical investigations. Re-examination of the experimental data is urgently required.

\section{CONCLUSIONS}

Following up our previous MRCISD calculations, we have performed GOSCI calculations on GdF. Relativistic effects are taken into consideration through the DiracCoulomb Hamiltonian in HF and GOSCI where the neardegeneracy effect of the $4 f$ molecular spinors is considered. To compare the electronic transitions with the experimental result of Kaledin et al., ${ }^{7}$ we have eliminated unimportant transitions with the help of the calculated transition probabilities. Comparing the present result with our previous MRCISD study, ${ }^{15}$ we have succeeded in clarifying the characters of the low-lying excited states of GdF. In particular, the characters of the [15.8] and [18.3] states have been elucidated. The transitions between the excited states have been classified according to the $\Delta \Omega$ values and a reassignment is proposed to the spectra due to the de-excitations to the states at $0.55 \mathrm{eV}$ above the ground state.

\section{ACKNOWLEDGMENTS}

The author (H.T.) was supported by Grants-in-Aid for Scientific Research (No. 16080216) from the Ministry of Education, Culture, Sports, Science and Technology of Japan, that is obtained under the leadership of Professor Machida of Osaka University and Professor Sato of Tohoku University.

\section{APPENDIX: WEIGHTS OF CONFIGURATION GROUPS ESTIMATED FROM GAOPs}

At first we examine the HF/DC molecular spinors of the GdF cation because this spinor set is used as basis for GOSCI. The GAOPs imply that a single electron occupation of the $6 s$-like molecular spinors gives approximately $[6 s]^{0.83}[5 d]^{0.05}[6 p]^{0.12}$. Also a single electron occupation of the $5 d$-like molecular spinors gives $[5 d]^{\mathrm{n} 5 \mathrm{~d}}[6 p]^{\mathrm{n} 6 \mathrm{p}}$. Here atomic spinors and molecular spinors are surrounded by square brackets and parentheses, respectively. For the two $5 d$-like molecular spinors, $\mathrm{n} 5 \mathrm{~d}$ is almost 1.0 (purely $\mathrm{Ce}$ 
atomic $5 d$-like). For the remaining three $5 d$-like molecular spinors, $n 5 d$ and $n 6 p$ are around 0.5 (some atomic $6 p$-like).

We found that the three excited states of $\mathrm{GdF}(\mathrm{SN}=75$, 84, and 108 in Table IV) are almost composed of the two configuration groups of $(4 f)^{7}(5 d)^{1}(6 s)^{1}$ and $(4 f)^{7}(5 d)^{2}$. We can approximately determine the weights of $A^{2}$ and $B^{2} \quad(=1$ $-A^{2}$ ) for $(4 f)^{7}(5 d)^{1}(6 s)^{1}$ and $(4 f)^{7}(5 d)^{2}$ through the GAOPs of GOSCI.

$$
\begin{aligned}
{[4 f]^{7}[5 d]^{n 5 d}[6 p]^{n 6 p}[6 s]^{n 6 s} } \\
=A^{2}[4 f]^{7}[5 d]^{n 5 d^{\prime}}[6 p]^{n 6 p^{\prime}}[6 s]^{0.83}+\left(1-\mathrm{A}^{2}\right) \\
\quad \times[4 f]^{7}[5 d]^{n 5 d^{\prime \prime}}[6 p]^{n 6 p^{\prime \prime}} .
\end{aligned}
$$

The values of $n 5 d^{\prime}, n 6 p^{\prime}, n 5 d^{\prime \prime}$, and $n 6 p^{\prime \prime}$ can be obtained by simple arithmetic, but their actual values are not needed here. The values of $n 5 d, n 6 p$, and $n 6 s$ depend on the state and are listed in Table IV. Solving Eq. (A1) gives $A^{2}=n 6 s / 0.83$. Then we have $A^{2}=0.55,0.54$, and 0.62 for the first $(\Omega$ $=5 / 2)$, the second $(\Omega=9 / 2)$, and the third $(\Omega=7 / 2)$ excited states. In this way, we can ascribe the double minima in the PECs shown in Fig. 1 to the contributions from the two configuration groups of $(4 f)^{7}(5 d)^{1}(6 s)^{1}$ and $(4 f)^{7}(5 d)^{2}$.

${ }^{1}$ R. F. Barrow, M. W. Bastin, D. L. G. Moore, and C. J. Pott, Nature (London) 215, 1072 (1967)

${ }^{2}$ P. D. Kleinschmidt, K. H. Lau, and D. L. Hildenbrand, J. Chem. Phys. 74, 653 (1981).

${ }^{3}$ M. Dulick, R. Field, J. Cl. Beaufils, and J. Schamps, J. Mol. Spectrosc. 87, 278 (1981).

${ }^{4}$ R. M. Clements and R. F. Barrow, J. Mol. Spectrosc. 107, 119 (1984).

${ }^{5}$ L. A. Kaledin, J. C. Bloch, M. C. McCarthy, L. V. Gurvich, and R. B. Field, Mol. Phys. 83, 881 (1994).

${ }^{6}$ L. A. Kaledin, J. E. McCord, M. C. Heaven, and R. F. Barrow, J. Mol. Spectrosc. 169, 253 (1995).
${ }^{7}$ L. A. Kaledin, J. C. Bloch, M. C. McCarthy, E. A. Shenyavskaya, and R. W. Field, J. Mol. Spectrosc. 176, 148 (1996).

${ }^{8}$ M. Dolg and H. Stoll, Theor. Chim. Acta 75, 369 (1989).

${ }^{9}$ S. G. Wang and W. H. E. Schwarz, J. Phys. Chem. 99, 11687 (1995).

${ }^{10} \mathrm{H}$. Tatewaki and O. Matsuoka, J. Chem. Phys. 106, 4558 (1997).

${ }^{11}$ M. Dolg, W. Liu, and S. Kalvoda, Int. J. Quantum Chem. 76, 359 (2000).

${ }^{12}$ X. Cao, W. Liu, and M. Dolg, Sci. China, Ser. B: Chem. 31, 481 (2001).

${ }^{13}$ T. Koga, H. Tatewaki, and O. Matsuoka, J. Chem. Phys. 117, 7813 (2002).

${ }^{14} \mathrm{H}$. Heiberg, O. Gropen, J. K. Laerdahl, O. Swang, and U. Wahlgren, Theor. Chem. Acc. 110, 118 (2003).

${ }^{15}$ H. Tatewaki, Y. Watanabe, S. Yamamoto, and E. Miyoshi, J. Chem. Phys. 125, 044309 (2006).

${ }^{16}$ O. Matsuoka, J. Chem. Phys. 96, 6773 (1992).

${ }^{17}$ Y. Watanabe and O. Matsuoka, J. Chem. Phys. 109, 8182 (1998).

${ }^{18}$ H. J. Aa. Jensen, T. Saue, L. Visscher et al., DIRAC, a relativistic ab initio electronic structure program, Release DIRAC04.0, 2004; http:// dirac.chem.sdu.dk

${ }^{19}$ J. Andzelm, M. Klobukowski, E. Radio-Andzelm, Y. Sakai, and H. Tatewaki, in Gaussian Basis Sets for Molecular Calculations, edited by S. Huzinaga (Elsevier, Amsterdam, 1984).

${ }^{20}$ O. Visser, L. Visscher, P. J. C. Aerts, and W. C. Nieuwpoort, J. Chem. Phys. 96, 2910 (1992).

${ }^{21}$ L. Visscher, O. Visser, P. J. C. Aerts, H. Merenga, and W. C. Nieuwpoort, Comput. Phys. Commun. 81, 120 (1994).

${ }^{22} \mathrm{H}$. Lefebvre-Brion and R. W. Field, The Spectra and Dynamics of Diatomic Molecules (Elsevier, Amsterdam, 2004).

${ }^{23}$ W. C. Martin, R. Zalubas, and L. Hagan, Natl. Stand. Ref. Data Ser. (U.S., Natl. Bur. Stand.) 60, 1978.

${ }^{24}$ H. Moriyama, Y. Watanabe, H. Nakano, and H. Tatewaki, J. Phys. Chem. A 112, 2683 (2008).

${ }^{25}$ H. Tatewaki, S. Yamamoto, Y. Watanabe, and H. Nakano, J. Chem. Phys. 128, 214901 (2008).

${ }^{26}$ K. P. Hubner and G. Herzberg, Molecular Spectra and Molecular Structure IV. Constants of Diatomic Molecules (Van Nostrand Reinhold, New York, 1978).

${ }^{27}$ M. Miyajima, Y. Watanabe, and H. Nakano, J. Chem. Phys. 124, 044101 (2006).

${ }^{28}$ C. Angeli, R. Cimiraglia, S. Evangelisti, T. Leininger, and J.-P. Malrieu, J. Chem. Phys. 114, 10252 (2001) 